\title{
Protocol of Taste and See: A Feasibility Study of a Church-Based, Healthy, Intuitive Eating Programme
}

\author{
Deborah Lycett $^{1, *}$, Riya Patel ${ }^{1}$, Anne Coufopoulos ${ }^{2}$ and Andy Turner ${ }^{1}$ \\ 1 Faculty of Health and Life Sciences, Coventry University, Priory Road, Coventry CV1 5FB, UK; \\ patelr34@uni.coventry.ac.uk (R.P.); hsx116@coventry.ac.uk (A.T.) \\ 2 Faculty of Health and Social Care, Edge Hill University, St Helen's Road, Ormskirk, Lancashire L39 4QP, UK; \\ Anne.Coufopoulos@edgehill.ac.uk \\ * Correspondence: Deborah.lycett@coventry.ac.uk; Tel.: +44-247-765-5938
}

Academic Editors: Fiona Timmins and Wilf McSherry

Received: 29 November 2015; Accepted: 15 April 2016; Published: 22 April 2016

\begin{abstract}
Obesity treatment remains a high global priority. Evidence suggests holistic approaches, which include a religious element, are promising. Most research is from the USA, but recent evidence suggests a need within the UK population. The aim of this study is to explore the feasibility of running and evaluating a Christian-based, healthy, intuitive-eating programme, in a UK church. This is the protocol of a mixed-methods single-group feasibility study of a ten-week programme. The programme focuses on breaking the "diet and weight regain" cycle using principles from intuitive eating uniquely combined with biblical principles of love, freedom, responsibility, forgiveness, and spiritual need. We will recruit at least ten adult participants who are obese, overweight, or of a healthy weight with problematic eating behaviours. Participants can be from any faith or none. Robust measures of physical, psychological and spiritual outcomes will be used. Results are not yet available. Findings will be used to design a cluster-randomised controlled trial to test efficacy through many churches. If weight reduces by a small amount, there will be substantial benefits to public health. With a strong association between obesity and mental-ill health, a holistic intervention is particularly important. Using churches addresses religious and spiritual health, and uses existing social structures and a voluntary workforce that are sustainable and cost-effective.
\end{abstract}

Keywords: obesity; religion; church-based intervention; faith-based; Christian; feasibility trial; UK

\section{Background: Obesity-What Has Religion Got to Do with It?}

It is projected that sixty percent of the world's population will be classified as either overweight or obese by 2030 [1]. This predicts obesity to be the largest chronic health problem globally. Obesity significantly increases the risk of non-communicable diseases such as diabetes mellitus, heart disease, chronic obstructive pulmonary disease [2] and several cancers [3]. Obesity is also associated with psychological stress and a bidirectional increased risk of depression, such that obesity may increase the risk of depression and depression may also increase the risk of obesity [4]. Together, scientific and social communities need to look at new ways to tackle the increased health and socio-economic burden of obesity.

The World Health Organisation, in its global strategy on diet, physical activity and health has recommended further exploration into the role of religious communities to tackle obesity through faith-based weight management programmes. Not only do these tap into existing social structures, but also, through mobilising the voluntary workforce and promoting self-management, they are potentially very cost effective [5].

Systematic review evidence from many observational studies suggests that religion is associated with a reduced risk of all-cause mortality, reduced risk of cardiovascular disease, greater well-being 
and happiness, less depression and faster recovery from depression and, in some studies, a lower rate of cancer [6]. Such associations may be mediated through lifestyle choices as those who are religious tend to smoke less and drink less alcohol. In some religions, these practices are prohibited and in Seventh-Day Adventists, for example, the use of a low fat, plant-based diet is associated with lower rates of chronic disease [7]. Benefits might also come about through spiritual or religious coping that provides resilience in the face of adversity or disease. This may result in reduced detriment to health and greater life satisfaction [8,9]. In addition, social support from religious communities may mediate some positive associations.

However, the evidence is not entirely consistent and many studies are of cross-sectional design or a qualitative nature, meaning causality between religious engagement and better health cannot be inferred [10]. Evidence of the impact of religion on health is particularly unclear in relation to obesity.

A systematic review of cross-sectional and prospective cohort studies up to 2010 found 36 studies investigating the association between religion or spirituality and body weight. Of these, seven (19\%) reported a lower body weight among those who associated themselves with a religion, fourteen (39\%) reported a higher body weight, two $(6 \%)$ had mixed results, and thirteen $(36 \%)$ found no association between body weight and religion. However, the highest quality cross-sectional studies found that religious involvement was associated with a higher Body Mass Index (BMI), but, in longitudinal studies, no association was found [6]. In addition, an inverse association between spiritual well-being and emotional eating has been demonstrated [11].

Nearly all the studies looking at spirituality, religion and obesity so far have been carried out in the USA. The first one in England was a cross-sectional study using Health Survey for England 2012 data. Findings showed that religious affiliation was associated with being more overweight $\left(0.91 \mathrm{~kg} / \mathrm{m}^{2}\right.$ higher BMI in those associated to a religion than those not associated to a religion) and the evidence of this association was strongest among those affiliated to a Christian religion [12]. Again, this was a cross-sectional study, and it cannot provide any suggestion of directionality i.e., do those who are more religious gain more weight or do those who experience unwanted weight gain find solace and acceptance in religion? However, it does suggest that those affiliated to the Christian faith might be an important population to target for obesity interventions, as some evidence suggests they are more likely to be overweight.

In the USA, obesity interventions have been developed to meet the needs of religious communities, and these have been almost exclusively for the African-American protestant community, who are at an increased risk of diabetes and access healthcare less often than the rest of the population. A systematic review [13], which included large cluster-randomised controlled trials of faith-based (adding a spiritual dimension by including bible study, prayer, journaling and spiritual themes) and faith-placed (occurring at a place of worship) church interventions found body weight loss occurred in seventy percent of these interventions. Sixty percent of the interventions reported increased fruit and vegetable intake and thirty-eight percent reported increased physical activity. However, more studies that are rigorous are still needed.

The church-based interventions to date, although adding a spiritual element, are essentially conventional in their approach to obesity. They focus primarily on achieving weight loss through dietary restriction. However, several systematic reviews have identified that following such weight loss; the majority of people do not sustain weight loss maintenance. One systematic review showed that over half the weight that was lost was regained at one-year follow-up [14]. Another showed that between one to two thirds of dieters regain more weight at a four-year follow-up and beyond than they initially lose [15]. Significant psychological consequences of poor weight loss maintenance have been suggested. Food restriction can lead to hunger and feelings of deprivation or preoccupation with food, which, in turn, may trigger overconsumption [16-18]. Overconsumption and weight gain may lead to feelings of low self-esteem, depression and guilt [19]. To manage feelings of guilt associated with overconsumption, further attempts may be made to restrict eating [20]. A cycle of dieting and 
overeating, weight loss and weight gain may be perpetuated, resulting in little long-term benefit to physical health and potentially a deterioration in mental well-being [21].

Is this therefore an ethical approach to obesity? Should we continue to focus on weight loss in all who are overweight or obese or does this lead to futile weight cycling, a heavy burden of guilt and poor mental-well-being? Could some individuals achieve a greater improvement in health and well-being if emphasis was on the maintenance of a healthy lifestyle and improved psychological and spiritual well-being, irrespective of weight loss?

Interventions have been developed to focus on the health gains of dietary change, physical activity and psychosocial well-being in those who are overweight or obese, rather than on weight loss alone [22]. These teach participants to eat intuitively in response to genuine hunger, to recognise satiety and avoid eating in response to negative emotion. They are positive and affirming, generating feelings of contentment that may lead to more-sustained lifestyle change. Pooling together the evidence for these provides promising results, but high quality studies are lacking [23]. While these approaches go some way to address both physical and psychological need, they do not address spiritual or religious needs.

In light of the need to address obesity with community-based interventions, the potential personal resources of spiritual and religious coping, the success of church based interventions in the USA, and evidence suggesting affiliation to the Christian religion in England is associated with increased BMI, exploration within UK churches is worthwhile. Conventional approaches to weight management, that focus on dietary restriction and weight loss, may lead to low self-esteem, guilt and poor weight loss maintenance. While intuitive eating programmes may provide a holistic alternative to these, adding a spiritual component, within a church setting, offers an opportunity for religious engagement, whereby, freedom from guilt and shame, which accompanies weight loss failure, can be explored from a Christian perspective.

\section{Aim}

We propose a unique study that investigates the feasibility of running and evaluating a UK church-based programme, called Taste and See, which combines intuitive eating elements with Christian principals of freedom from guilt, love, acceptance and help from God. This paper describes the protocol for such a study.

\section{Objectives}

- To determine how feasible it is to evaluate Taste and See within a UK church setting in preparation for developing a randomised controlled trial.

- To investigate change in physical, psychological and spiritual well-being in participants pre and post programme, and at six-month follow-up.

- To assess change in eating behaviour, nutritional intake and physical activity pre and post programme, and at six-month follow-up.

- To investigate participant acceptability of a Christian weight management programme to those who do not attend church or are not Christian.

\section{Design}

This study uses a one-group pretest-posttest design. The participants will attend once a week for approximately ten, 90-minute sessions. Participants will be followed up at the end of the programme and then again at six months.

\section{Participants}

While this intervention incorporates Christian beliefs, it is not exclusively for Christians. Anyone interested, regardless of their beliefs, may take part. We are particularly interested in the relevance of this programme to those who do not attend church, as many who affiliate themselves to the Christian 
religion in England do not attend church regularly [24]. We are also interested in the relevance of this to those who are not Christian, as evidence suggests those who are not religious, may still be interested in taking part in a programme based on Christian principles [25]. In addition, many people, from other faiths and none, attend churches for community events [26], so we do not want to exclude them from participating should they wish to.

\subsection{Inclusion Criteria}

In order to be eligible to take part in the study, individuals must be aged 18 years or over, and have a BMI greater than $25 \mathrm{~kg} / \mathrm{m}^{2}$. If during screening, participants' BMI is between 18.5 and $25 \mathrm{~kg} / \mathrm{m}^{2}$ and this is accompanied by a poor relationship with food, as measured by the three-factor eating scale (TFEQ-R21 [27]), they are still eligible to participate. The TFEQ-R21 scale covers three eating behaviours: uncontrolled eating, cognitive restraint and emotional eating. The questionnaire is a 21-item validated measure whereby high scores indicate the presence of problematic eating behaviours. Finally, participants should be able to read, understand and consent to study procedures.

\subsection{Exclusion Criteria}

Individuals fulfilling one or more of the following criteria are not eligible to participate. Those aged less than 18 years, pregnant, with a BMI less than 25 without evidence of problematic eating behavior or with a BMI less than $18.5 \mathrm{~kg} / \mathrm{m}^{2}$ are excluded. In addition, those suffering from any medical condition in which weight loss is contradicted, for example receiving chemotherapy, or those currently losing weight, intentionally or unintentionally, at a rate of $2 \mathrm{~kg}$ or more in the last four weeks are excluded.

\section{Recruitment Strategy}

Recruitment will be reflective of the ways in which individuals would naturally hear about church initiatives within the local community. For this reason, participation will be open to all who meet the inclusion criteria, and individuals will self-select and not be purposively sampled. We will test the feasibility of advertising the programme in the following ways:

- To the church congregation through: posters, the church newsletter, the church website and announcements at Sunday services.

- Outside of the congregation through: word of mouth invitations to interested friends and acquaintances.

- An article about the study and an invitation to participate will be placed in the parish council magazine, which is distributed to all households in the area.

\section{Sample Size}

As this is a feasibility study, we are investigating effect sizes in order to run an adequately powered randomised controlled trial. For feasibility purposes, we aim to recruit at least 10 participants to a programme. Ten participants would give us enough power to detect large differences in weight. It is possible that, over ten weeks, a weight loss outcome of $5 \mathrm{~kg}(\mathrm{SD}=5)$ would occur (a rate of $0.5 \mathrm{~kg}$ per week). In order to detect this with $80 \%$ power and an alpha level of 0.05 , a sample size of eight is required, which was calculated using an online sample size calculator designed by the University of California San Francisco (UCFS) Clinical and Translational Science Institute.

\section{Ethical Approval}

Ethical approval has been provided by Coventry University Research Ethics Committee. The trial will be conducted in accordance with the ethical guidelines of the British Psychological Society and the recommendations for clinicians involved in research on human subjects adopted by the 18th World Medical Assembly, Helsinki, 1964, and later revisions. 
All of the data collected for this study will be treated confidentially and stored securely in accordance with the Data Protection Act 1998. No participants will be identifiable from the results of the study, and participants will be given ID numbers to protect their identity and ensure analysis is blind.

\section{Information Session and Screening}

Potential participants will be invited to attend an information session one week before the programme starts. This session provides potential participants with a brief synopsis of the programme content, what is involved in evaluating the programme and an opportunity to ask questions. Participants will be given information sheets to take away and read, and a seven-day food diary to complete should they decide to take part.

Potential participants will also be screened during this session. Participants' BMI will be measured and the three factor eating questionnaire (for those with a BMI between 18.5 and $25 \mathrm{~kg} / \mathrm{m}^{2}$ ) completed to determine eligibility.

If potential participants choose to take part, they will return the following week when their informed consent, followed by baseline measurements, will be collected.

\section{Taste and See Programme Details}

This programme has been developed on the theoretical underpinning which comes from the cycle of dieting and weight regain, as described in the background section of this paper (red in Figure 1). To break this cycle, we have incorporated principles of intuitive eating (yellow in Figure 1), and mapped a Christian perspective from the Bible onto this, one which explores freedom, responsibility, forgiveness, and spiritual needs (green in Figure 1).

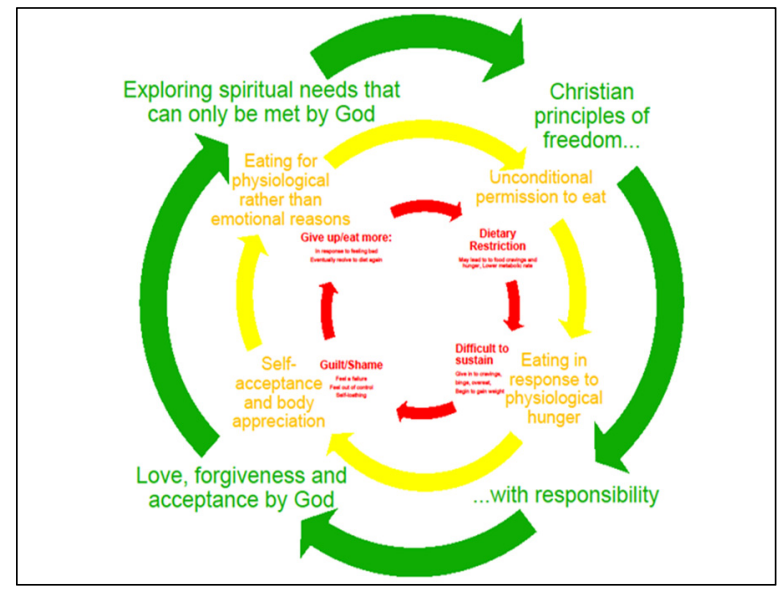

Figure 1. Theoretical underpinning of the Taste and See Programme.

The intervention consists of approximately ten, $90 \mathrm{~min}$, weekly sessions which take participants on a journey from identifying problematic eating behaviours to begin making changes. Each week, there is a theme (Table 1) and the following elements are included:

- Scientific content of evidence-based dietetic practice,

- Group activities to consider application of these dietetic principles in participants' own lives,

- Biblical view on the issues raised,

- Opportunity, without obligation, to respond individually to spiritual content if participants wish to do so,

- Activity for the week to practice making health behavior changes,

- Daily Bible reading and prayer material for those who want to engage with this. 
Table 1. Content and behavior change techniques of Taste and See.

\begin{tabular}{|c|c|c|c|}
\hline Session & Key Points, Activities and (Key Behaviour Change Techniques) & Scientific Principle & Biblical Principle \\
\hline \multicolumn{4}{|l|}{ Session 1: Your Relationship with Food } \\
\hline $\begin{array}{l}\text { To develop an awareness of self, of eating habits } \\
\text { and of a God who cares about this }\end{array}$ & $\begin{array}{l}\text { Everyone in the group has a similar problem (social support-general and } \\
\text { emotional); this is something that you can involve God in, if you would like to } \\
\text { (conserving mental resources). } \\
\text { Complete food and mood diary (self-monitoring of behaviour) }\end{array}$ & $\begin{array}{l}\text { The holistic aspects of eating The } \\
\text { evidence for addressing the spiritual } \\
\text { in weight management. }\end{array}$ & $\begin{array}{l}\text { We are physical and spiritual } \\
\text { beings. God loves us and wants } \\
\text { to be involved in our lives }\end{array}$ \\
\hline \multicolumn{4}{|l|}{ Session 2: What dietary rules do you follow? } \\
\hline $\begin{array}{l}\text { To introduce intuitive eating versus } \\
\text { dietary restriction }\end{array}$ & $\begin{array}{l}\text { Dietary rules can be unhelpful, find out what yours are and consider whether } \\
\text { they help or hinder you. What are the alternatives? (self-talk, reframing, } \\
\text { cognitive dissonance, regulate negative emotions, behaviour substitution, habit } \\
\text { reversal and formation, health consequences, emotional consequences, self-assessment } \\
\text { of affective consequences, action planning). }\end{array}$ & $\begin{array}{l}\text { The diet and weight regain cycle } \\
\text { The evidence for finding what } \\
\text { approach suits you } \\
\text { The evidence for intuitive eating }\end{array}$ & $\begin{array}{l}\text { Freedom with responsibility } \\
\text { "Everything permissible but not } \\
\text { everything is beneficial" }\end{array}$ \\
\hline \multicolumn{4}{|l|}{ Session 3: Are you really hungry? } \\
\hline To identify hunger and fullness & $\begin{array}{l}\text { Do you eat when you are full? } \\
\text { Activities to practice listening to your body signals of hunger and fullness } \\
\text { (anticipated regret, behavioural rehearsal, anticipation of future reward, } \\
\text { avoidance-changing exposure to cues for the behaviour, self-monitoring of behaviour, } \\
\text { action planning and implementation intentions). }\end{array}$ & $\begin{array}{l}\text { Hormonal regulation of appetite } \\
\text { What is a healthy diet? }\end{array}$ & $\begin{array}{l}\text { Created by God } \\
\text { A time for everything }\end{array}$ \\
\hline \multicolumn{4}{|l|}{ Session 4: Enjoying food again } \\
\hline To feel free to enjoy food & $\begin{array}{l}\text { Practice eating attentively, enjoy what you are eating, stop when you have } \\
\text { finished. Is it appropriate to feel guilty? (behaviour rehearsal, anticipating reward, } \\
\text { restructuring of the physical environment, goal setting, habit formation, regulate } \\
\text { negative emotions) }\end{array}$ & $\begin{array}{l}\text { Evidence for eating attentively, } \\
\text { reducing distractions } \\
\text { mindful eating exercise }\end{array}$ & $\begin{array}{l}\text { The blessings of God, he loves to } \\
\text { give us good gifts }\end{array}$ \\
\hline \multicolumn{4}{|l|}{ Session 5: Why else do we eat? } \\
\hline $\begin{array}{l}\text { To understand impulsive responses to feel } \\
\text { happier, to feel less bored, to reduce stress }\end{array}$ & $\begin{array}{l}\text { To identify times when we eat in response to emotion (self-monitoring of } \\
\text { behaviour, action planning and implementation intentions, emotional consequence, } \\
\text { self-assessment of affective consequences, self-talk, reframing, cognitive dissonance) }\end{array}$ & Dopamine pathway & $\begin{array}{l}\text { The reality of life in an imperfect } \\
\text { world/why things went wrong }\end{array}$ \\
\hline \multicolumn{4}{|l|}{ Session 6: What can we do instead? } \\
\hline $\begin{array}{l}\text { To identify ways to tackle boredom, stress and } \\
\text { low mood }\end{array}$ & $\begin{array}{l}\text { Plan alternative approaches, set clear goals of what to do differently this week } \\
\text { in response to a specific trigger (distraction, avoidance-changing exposure to cues } \\
\text { for the behaviour, goal setting, behaviour substitution habit reversal and formation } \\
\text { action planning and implementation intentions, problem solving and coping } \\
\text { planning, regulate negative emotions, self-talk, reframing) }\end{array}$ & $\begin{array}{l}\text { Evidence based physical activity and } \\
\text { relaxation suggestions }\end{array}$ & $\begin{array}{l}\text { Spiritual coping } \\
\text { Hope in difficult times }\end{array}$ \\
\hline
\end{tabular}


Table 1. Cont.

\begin{tabular}{|c|c|c|c|}
\hline Session & Key Points, Activities and (Key Behaviour Change Techniques) & Scientific Principle & Biblical Principle \\
\hline \multicolumn{4}{|l|}{ Session 7: Leaving the past behind } \\
\hline $\begin{array}{l}\text { To identify past hurts or habits that still } \\
\text { influence our relationship with food today, to } \\
\text { find healing in forgiveness }\end{array}$ & $\begin{array}{l}\text { Practice forgiveness } \\
\text { (self-monitoring, self-assessment of affective consequences, self-talk, reframing, } \\
\text { cognitive dissonance, regulate negative emotions, problem solving and coping } \\
\text { planning, behaviour rehearsal, self-affirmation) }\end{array}$ & $\begin{array}{l}\text { Evidence of the impact of adverse } \\
\text { child events } \\
\text { Evidence for forgiveness }\end{array}$ & "Forgive us as we forgive others" \\
\hline \multicolumn{4}{|l|}{ Session 8: You are loved and you are lovely } \\
\hline To understand the truth of who you are & $\begin{array}{l}\text { You are valued and loved for who you are (self-affirmation, verbal persuasion to } \\
\text { boost self-efficacy, identity associated with changed behaviour, social } \\
\text { support-emotional, self-talk, reframing, cognitive dissonance, regulate } \\
\text { negative emotions) }\end{array}$ & $\begin{array}{l}\text { Body congruence } \\
\text { Tips to build self-esteem }\end{array}$ & God's love and acceptance \\
\hline \multicolumn{4}{|l|}{ Session 9: Moving forward } \\
\hline $\begin{array}{l}\text { To consolidate new attitudes and behaviours, to } \\
\text { identify specific aspects of healthy living to } \\
\text { work on }\end{array}$ & $\begin{array}{l}\text { It takes time and practice, but we have supernatural help (conserving mental } \\
\text { resources, self-affirmation, verbal persuasion to boost self-efficacy, identity associated } \\
\text { with changed behaviour, social support-emotional, self-talk, reframing, cognitive } \\
\text { dissonance, regulate negative emotions, goal setting, behaviour substitution, habit } \\
\text { formation, action planning and implementation intentions, problem solving and } \\
\text { coping planning, distraction) }\end{array}$ & $\begin{array}{l}\text { Goal setting } \\
\text { Habit formation } \\
\text { Tips and ideas for a healthy lifestyle }\end{array}$ & $\begin{array}{l}\text { New creation, with God's spirit } \\
\text { at work within us }\end{array}$ \\
\hline \multicolumn{4}{|l|}{ Session 10: Pressing on/The future } \\
\hline $\begin{array}{l}\text { To equip participants to be able to continue the } \\
\text { Taste and See principles without weekly support }\end{array}$ & $\begin{array}{l}\text { It won't always be easy, but we can live in forgiveness and freedom } \\
\text { (self-affirmation, identity associated with changed behaviour, self-talk, reframing, } \\
\text { cognitive dissonance, regulate negative emotions, goal setting, behaviour substitution, } \\
\text { habit formation, action planning and implementation intentions, problem solving and } \\
\text { coping planning, distraction, anticipation of future reward, avoidance-changing } \\
\text { exposure to cues for the behaviour) }\end{array}$ & $\begin{array}{l}\text { Identifying and planning for lapses } \\
\text { Evidence for behaviour } \\
\text { change maintenance }\end{array}$ & Pressing on and managing failure \\
\hline
\end{tabular}


The programme incorporates 25 behavior change techniques (Table 1) from the taxonomy of behavior change [28].

\section{Ongoing Support and Follow-up}

Following programme completion participants may choose to continue to meet and offer informal peer support to one another. Participants will be followed up at the six-month point, and this will be noted.

\section{Group Facilitators}

The programme has been written so that content can to be delivered and facilitated by church members without a health professional background. Facilitators will be volunteers who have an interest in helping people with weight management. They will have good interpersonal and leadership skills evidenced by their own profession or by pastoral work or group leadership that they engage in with the church community. Programme materials, in the form of pre-written presentations, set group tasks and reading materials for participants, will be provided to ensure expected content is delivered. The study dietitian will demonstrate initial sessions and facilitators will take on more responsibility for delivery as the programme progresses. The study dietitian, who will be available throughout to support and address facilitator concerns, will also check fidelity through observation. Group facilitators will also receive basic training provided by a registered dietitian, church minister and qualified counsellor in the following areas:

- The need for an ethical code of conduct regarding good clinical practice and spiritual diversity,

- The importance of good group facilitation and communication skills,

- Broad principals of intuitive eating and the need to support participants' own behaviour change solutions rather than provide advice.

- Basic principles of a healthy diet and recommended physical activity levels as defined by the National Institute of Health and Care Excellence.

- When to refer on to a professional counsellor or General Medical Practitioner,

- The importance of collecting data and evaluation procedures.

\section{Measures}

All measures (except for demographics which will be taken at baseline only) will be taken at baseline, at the end of the programme, and six months following the end of the programme.

\subsection{Demographics}

These include participant's age, gender, ethnicity and socio-economic status.

\subsection{Height, Weight, Percentage Body Fat and Blood Pressure}

Participants weight and body fat will be measured using an Omron BF510 Body Composition Monitor (Omron Healthcare, Hoofddorp, the Netherlands). Height will be measured using the Leicester Height Measure, a standardized measure for determining height. Blood pressure will be measured using an automatic Omron M6 upper arm blood pressure monitor (Omron Healthcare, Hoofddorp, the Netherlands). Two measurements of blood pressure will be taken and the mean of the two readings will be used for data analysis purposes.

\subsection{Depression, Anxiety and Mental Well-Being}

Participant anxiety and depression will be measured using the validated questionnaires. These are the Generalised Anxiety Disorder (GAD-7) [29] and the Patient Health Questionnaire (PHQ-9) [30], respectively. Mental well-being will be measured using the validated Warwick-Edinburgh mental well-being scale (WEMWBS) [31]. 


\subsection{Eating Behaviour}

The validated three-factor eating questionnaire (TFEQ-R21) [27] will be used to measure eating behavior and identify patterns of disordered eating and changes in these. The revised intuitive eating scale (2nd edition) (IES-2) will be used to measure intuitive eating [32].

\subsection{Spiritual Well-Being}

Spiritual well-being will be measured using the spiritual well-being scale. This is a 20-item instrument comprised of two subscales of ten items. The first subscale, religious well-being, assesses individuals' experiences of having a satisfying relationship with God or a higher being. The second subscale, existential well-being, examines an individuals' sense of life satisfaction and purpose. Even though this spiritual well-being scale has been shown to have ceiling effects within evangelical Christian samples in particular, we have chosen it as it has good face validity and is a good general measure of spiritual well-being across a mixed sample [33]. We are using it, as one of several measures, to provide a full assessment of spiritual and religious well-being.

\subsection{Religious Well-Being}

Religious well-being, as distinct from spiritual well-being (which can overlap with mental well-being), can be defined as the quality of a relationship with God or a higher power, in terms of feeling loved by and close to God.

This will be measured by the four item religious love subscale from the validated Sorokin multidimensional inventory of love experience (SMILE) [34].

\subsection{Religiosity}

Religiousness has three major dimensions: organisational, non-organisational and subjective or intrinsic religiosity. The intrinsic measure of religiosity will be assessed using the religious and spiritual well-being measures as described above. The following scales will be used to measure organisational and non-organisational religious dimensions. The first two items of the Duke University Religion Index (DUREL) [35] will be used to measure religious involvement, such as, church attendance. This measures the organisational dimension of religiousness. To measure non-organisational dimension, an adapted version of the religious support scale [36] will be used so that it refers to the group taking part in the programme, rather than a religious congregation as a whole.

\subsection{Physical Activity}

Physical activity will be measured using the Stanford seven-day physical activity recall [37]. The Stanford seven-day recall is a robust measure, measuring both work-related and non-work-related physical activity. It is a well-validated measure that assesses the level of habitual physical activity through identifying the time individuals spend engaging in light, moderate, hard and very hard activity as well as sleep. The measure has demonstrated high correlations between physical activity diary records and interview administered recall [38] and is suitable for assessing changes in individual physical activity levels. While objective measures of physical activity, such as accelerometers, would be the most robust measure, we chose not to use these, because accelerometer use would be impractical in the large-scale trial that this feasibility study will inform.

\subsection{Nutrient Intake}

Nutrient intake is determined by a detailed seven-day food intake diary. Participants are encouraged to weigh their food when completing the seven-day food diary. Despite under-reporting in obese individuals, a seven-day weighed intake diary continues to be the most accurate measure of dietary intake and is sensitive to individual changes in nutrient composition [39,40]. 


\subsection{Participant Acceptability}

Participant acceptability will be measured quantitatively by response and attrition rates, and qualitatively by semi-structured interviews. Following completion of, or a participant dropping out of, the intervention, short semi-structured face-to-face interviews will be conducted. Participants will be asked to discuss which aspects of the intervention they found most and least helpful. All the interviews will be audio-recorded and transcribed verbatim.

\subsection{Facilitator Feasibility}

Facilitators will also be interviewed to explore their experiences of delivering the intervention, e.g., ease of delivery, sufficiency of training and difficulties encountered.

\section{Data Analysis}

Change in clinical measures, psychological and spiritual well-being scales will be presented using descriptive statistics. The significance of these changes over time will be analysed using inferential statistics. Significance will be set at the $5 \%$ level, exact $p$-values will be given and $95 \%$ confidence intervals where appropriate. Analysis will be conducted on an intention to treat basis, with missing data being conservatively input using baseline observation carried forward (BOCF). Data will be collected and analysed using the statistical software IBM SPSS Statistics programme (International Business Machines Corporation, New York, NY, USA). Multivariate regression modelling will be used to investigate associations with change in outcome variables.

Semi-structure interviews will be transcribed verbatim. The data will be analysed using thematic analysis where the data will be coded according to content and analysed for common themes. Qualitative software NVIVO 11 (Qualitative Research Software International, Melbourne, Australia) will be used to organise and track the data.

\section{Implementation of Conclusions}

We anticipate that the findings of this study will be used to design a larger cluster-randomised controlled trial to test the efficacy of this intervention, which is rolled out by churches, in local communities.

If weight can be reduced, even by a small amount, the impact across communities and on public health could be substantial. Modelling has shown that a $1 \%$ reduction in BMI, which is equivalent to a weight loss of approximately $1 \mathrm{~kg}$ for an adult of average weight, would have a substantial effect on consequent health burdens. Compared with a scenario in which recent trends continue, a $1 \%$ BMI reduction across the UK would avoid 179,000-202,000 incident cases of diabetes, 122,000 cardiovascular diseases, and 32,000-33,000 incident cases of cancer with a gain of about 3 million Quality Adjusted Life-Years (QALYs) over 20 years. In addition to improving the healthy, productive life span of the population, this would make a significant dent on the projected additional health-care cost of $£ 1.9-2$ billion a year in the UK by 2030 [41].

The economic and social costs of mental health problems in England were estimated at $£ 105$ billion in 2009-2010; taking into account costs for health and social care, loss of output and human costs. The economic benefits of mental wellbeing are not as well established as the costs of mental illness; however, improving mental well-being increases psychosocial functioning, lowers healthcare use, and reduces morbidity and premature mortality. With a strong association between obesity and poor mental health [4], an intervention addressing the mental health of those who are obese is particularly important. Using churches enables religious and spiritual health to be addressed and uses existing social structures with a voluntary workforce that are potentially sustainable and cost effective.

While weight management programmes have been shown to be important in African-American churches within the US, this has not been demonstrated elsewhere. In addition, the programme we have developed is unique in its Christian focus on freedom from guilt, shame and "dietary failure". 
Author Contributions: D.L. conceived, designed and executed the study; R.P. contributed to drafting the protocol and collected the data; A.C. and A.T. contributed to the design of the study and drafting of the paper.

Conflicts of Interest: The authors declare no conflict of interest.

\section{References}

1. Frühbeck, Gema, and Volkan Yumuk. "Obesity: A Gateway Disease with a Rising Prevalence." Obesity Facts 7 (2014): 33-36. [CrossRef] [PubMed]

2. Finer, Nicholas. "Medical consequences of obesity." Medicine 39 (2011): 18-23. [CrossRef]

3. World Cancer Research Fund/American Institute for Cancer Research. Food, Nutrition, Physical Activity, and the Prevention of Cancer: A Global Perspective. Washington: AICR, 2007.

4. Luppino, Floriana S., Leonore M. de Wit, Paul F. Bouvy, Theo Stijnen, Pim Cuijpers, Brenda WJH Penninx, and Frans G. Zitman. "Overweight, obesity, and depression: A systematic review and meta-analysis of longitudinal studies." Archives of General Psychiatry 67 (2010): 220-29. [CrossRef] [PubMed]

5. WHO. Interventions on Diet and Physical Activity: What Works: Summary Report. Geneva: WHO, 2009.

6. Koenig, Harold, Dana King, and Verna B. Carson. Handbook of Religion and Health, 2nd ed. New York: Oxford University Press, 2012.

7. Fraser, Gary E. “Diet as primordial prevention in Seventh-Day Adventists." Preventive Medicine 29 (1999): S18-S23. [CrossRef] [PubMed]

8. Banthia, Rajni, Judith Tedlie Moskowitz, Michael Acree, and Susan Folkman. "Socioeconomic differences in the effects of prayer on physical symptoms and quality of life." Journal of Health Psychology 12 (2007): 249-60. [CrossRef] [PubMed]

9. Gauthier, Kristopher J., Andrew N. Christopher, Mark I. Walter, Ronney Mourad, and Pam Marek. "Religiosity, religious doubt, and the need for cognition: Their interactive relationship with life satisfaction." Journal of Happiness Studies 7 (2006): 139-54. [CrossRef]

10. King, Michael. "The Challenge of Research into Religion and Spirituality (Keynote 1)." Journal for the Study of Spirituality 4 (2014): 106-20. [CrossRef]

11. Hawks, Steven R., Marylynn B. Goudy, and Julie A. Gast. “Emotional Eating and Spiritual Well-Being: A Possible Connection? " American Journal of Health Education 34 (2003): 30-33. [CrossRef]

12. Lycett, Deborah. "The Association of Religious Affiliation and Body Mass Index (BMI): An Analysis from the Health Survey for England." Journal of Religion and Health 54 (2014): 1-19.

13. Lancaster, Kristie, Lori Carter-Edwards, Stephanie Grilo, Chwan Li Shen, and Antoinette Schoenthaler. "Obesity interventions in African American faith-based organizations: A systematic review." Obesity Reviews 15 (2014): 159-76. [CrossRef] [PubMed]

14. Barte, Jeroen, Nancy Ter Bogt, Rik Bogers, Pedro Teixeira, Bryan Blissmer, Trevor Mori, and Wanda Bemelmans. "Maintenance of weight loss after lifestyle interventions for overweight and obesity, a systematic review." Obesity Reviews 11 (2010): 899-906. [CrossRef] [PubMed]

15. Mann, Traci, A. Janet Tomiyama, Erika Westling, Ann-Marie Lew, Barbra Samuels, and Jason Chatman. "Medicare's Search for Effective Obesity Treatments: Diets are Not the Answer." American Psychologist 62 (2007): 220-33. [CrossRef] [PubMed]

16. Polivy, Janet, Julie Coleman, and C. Peter Herman. "The effect of deprivation on food cravings and eating behavior in restrained and unrestrained eaters." International Journal of Eating Disorders 38 (2005): 301-9. [CrossRef] [PubMed]

17. Stroebe, Wolfgang, Guido M. van Koningsbruggen, Esther K. Papies, and Henk Aarts. "Why most Dieters Fail but some Succeed: A Goal Conflict Model of Eating Behavior.” Psychological Review 120 (2013): 110-38. [CrossRef] [PubMed]

18. Houben, Katrijn, Anne Roefs, and Anita Jansen. “Guilty pleasures II: Restrained eaters' implicit preferences for high, moderate and low-caloric food." Eating Behaviors 13 (2012): 275-77. [CrossRef] [PubMed]

19. Dubé, Laurette, Jordan L. LeBel, and Ji Lu. "Affect asymmetry and comfort food consumption." Physiology $\mathcal{E}$ Behavior 86 (2005): 559-67. [CrossRef] [PubMed]

20. Buchanan, Kiera, and Jeanie Sheffield. "Why do diets fail?: An exploration of dieters' experiences using thematic analysis." Journal of Health Psychology. Published electronically 16 December 2015. [CrossRef] [PubMed] 
21. Petroni, Maria Letizia, Nicola Villanova, Sebastiano Avagnina, Maria Antonia Fusco, Giuseppe Fatati, Angelo Compare, Giulio Marchesini, and QUOVADIS Study Group. "Psychological distress in morbid obesity in relation to weight history." Obesity Surgery 17 (2007): 391-99. [CrossRef] [PubMed]

22. Bacon, Linda, Judith S. Stern, Marta D. van Loan, and Nancy L. Keim. "Size acceptance and intuitive eating improve health for obese, female chronic dieters." Journal of the American Dietetic Association 105 (2005): 929-36. [CrossRef] [PubMed]

23. Khasteganan, Nazanin, Deborah Lycett, Andy Turner, Amanda Farley, Nicola Lindson-Hawley, and Gill Furze. "Health, not weight loss, focused versus conventional weight loss programmes for cardiovascular risk factors: Protocol for a Cochrane Review." Cochrane Database of Systematic Reviews 7 (2014): CD011182.

24. Ashworth, Jacinta, and Ian Farthing. Churchgoing in the UK. A Research Report from Tearfund on Church Attendance in the UK. London: Tearfund, 2007.

25. Ronel, Natti, and Galit Libman. "Eating Disorders and Recovery: Lessons from Overeaters Anonymous." Clinical Social Work Journal 31 (2003): 155-71. [CrossRef]

26. ChurchCare. “Open and Sustainable." 2012. Available online: http://www.churchcare.co.uk/churches/ open-sustainable (accessed on 11 February 2016).

27. Karlsson, Jan, Lars-Olof Persson, Lars Sjöström, and Marriane Sullivan. "Psychometric properties and factor structure of the Three-Factor Eating Questionnaire (TFEQ) in obese men and women. Results from the Swedish Obese Subjects." International Journal of Obesity Related Metabolic Disorder 24 (2000): 1715-25. [CrossRef]

28. Michie, Susan, Michelle Richardson, Marie Johnston, Charles Abraham, Jill Francis, Wendy Hardeman, Martin P. Eccles, James Cane, and Caroline E. Wood. "The behavior change technique taxonomy (v1) of 93 hierarchically clustered techniques: Building an international consensus for the reporting of behavior change interventions." Annals of Behavioral Medicine 46 (2013): 81-95. [CrossRef] [PubMed]

29. Spitzer, Robert L., Kurt Kroenke, Janet B. W. Williams, and Bernd Löwe. "A brief measure for assessing generalized anxiety disorder: The GAD-7." Archives of Internal Medicine 166 (2006): 1092-97. [CrossRef] [PubMed]

30. Kroenke, Kurt, and Robert L. Spitzer. "The PHQ-9: A new depression diagnostic and severity measure." Psychiatric Annals 32 (2002): 509-21. [CrossRef]

31. Tennant, Ruth, Louise Hiller, Ruth Fishwick, Stephen Platt, Stephen Joseph, Scott Weich, Jane Parkinson, Jenny Secker, and Sarah Stewart-Brown. "The Warwick-Edinburgh mental well-being scale (WEMWBS): Development and UK validation." Health and Quality of Life Outcomes 5 (2007): 63-73. [CrossRef] [PubMed]

32. Tylka, Tracy L., and Ashley M. Kroon van Diest. "The Intuitive Eating Scale-2: Item Refinement and Psychometric Evaluation with College Women and Men." Journal of Counseling Psychology 60 (2013): 137-53. [CrossRef] [PubMed]

33. Bufford, Rodger K., Raymond F. Paloutzian, and Craig W. Ellison. "Norms for the spiritual well-being scale." Journal of Psychology and Theology 19 (1991): 56-70.

34. Levin, Jeff, and Berton H. Kaplan. “The sorokin multidimensional inventory of love experience (SMILE): Development, validation, and religious determinants." Review of Religious Research 51 (2010): 380-401.

35. Koenig, Harold G., and Arndt Büssing. "The duke university religion index (DUREL): A five-item measure for use in epidemological studies." Religions 1 (2010): 78-85. [CrossRef]

36. Krause, Neal. Religious Support. Multidimensional Measurement of Religiousness/Spirituality for Use in Health Research: A Report of the Fetzer Institute/National Institute on Aging Workshop Group. Kalamazoo: Fetzer Foundation, 1999.

37. Sallis, James F., William L. Haskell, Peter D. Wood, Stephen P. Fortmann, Todd Rogers, Steven N. Blair, and Ralph S. Paffenbarger. "Physical activity assessment methodology in the Five City Project." American Journal of Epidemiology 121 (1985): 91-106. [PubMed]

38. Dishman, Rod, and Mary Steinhardt. "Reliability and concurrent validity for a 7-d recall of physical activity in college students." Medical Science Sports E Exercise 20 (1988): 14-25. [CrossRef]

39. Bingham, Sheila, Aedin Cassidy, Timothy Cole, Ailsa Welch, Shirley Runswick, Alison Black, David Thurnham, Chris Bates, Kay-Tee Khaw, Timothy Key, and et al. "Validation of weighed records and other methods of dietary assessment using the $24 \mathrm{~h}$ urine nitrogen technique and other biological markers." British Journal of Nutrition 73 (1995): 531-50. [CrossRef] [PubMed] 
40. Wrieden, Wendy, Heather Peace, Julie Armstrong, and Karen Barton. "A short review of dietary assessment methods used in National and Scottish Research Studies." 2003. Available online: http:/ / www.food.gov.uk/sites/default/files/multimedia/pdfs/scotdietassessmethods.pdf (accessed on 19 April 2016).

41. Wang, Y. Claire, Klim McPherson, Tim Marsh, Steven L. Gortmaker, and Martin Brown. "Health and economic burden of the projected obesity trends in the USA and the UK." The Lancet 378 (2011): 815-25. [CrossRef]

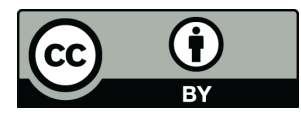

(c) 2016 by the authors; licensee MDPI, Basel, Switzerland. This article is an open access article distributed under the terms and conditions of the Creative Commons Attribution (CC-BY) license (http://creativecommons.org/licenses/by/4.0/). 